\title{
A importância da fala sobre a morte para pacientes oncológicos em fase terminal à luz da psicanálise
}

\section{L'importance de la parole au décès pour les patients atteints d'un cancer en phase agonisante à la lumière de la psychanalyse}

\author{
Miriam Carvalho da Silva ${ }^{1 *}$, Priscila dos Santos Pereira Cardoso ${ }^{2}$ \\ 1 Psicóloga, Especializanda em Políticas educacionais pela Universidade Federal do Amapá-UNIFAP. Macapá-AP Brasil. E-mail: \\ miriampsic96@gmail.com *Autor para correspondência. \\ ${ }_{2}$ Psicóloga/Psicanalista, Especialista em Saúde Mental e Atenção Psicossocial pela Universidade Estácio de Sá. Especialista em Docência na \\ Educação Superior pelo Instituto de Ensino Superior do Amapá-IESAP, Macapá-AP Brasil. Mestranda em Psicologia pela Universidade Federal \\ do Pará-UFPA. Linha de pesquisa: Psicanalise: teoria e clínica.E-mail: priscilapereira96@hotmail.com
}

Palavras-chave
Psicanálise
Morte
Fala
Câncer

\section{Keywords}

Psychanalyse

La mort

Parle

Cancer

\begin{abstract}
Esta pesquisa se propôs a trabalhar a importância da fala sobre a morte para pacientes oncológicos em fase terminal, a partir de uma visão psicanalítica. Foi realizada uma pesquisa bibliográfica, tendo como objetivo analisar a luz da psicanálise a relevância do falar para o paciente oncológico em fase terminal, realizou-se a relação entre a prevalência da pulsão de vida e pulsão de morte no paciente oncológico em fase terminal e o significado que o significante câncer possui para o sujeito. Tornou-se notória a importância da fala para os pacientes oncológicos em fase terminal, levando a refletir sobre a urgência de vida do sujeito, promovendo por meio da fala, a elaboração do luto devido às perdas ocorridas e a retificação subjetiva.

Cette recherche proposait de bosser sur l"importance du discours sur le décès chez les patients cancéreux en phase terminale, d'un point de vue psychanalytique. Une recherche bibliographique a été réalisée dans le but d'analyser la lumière de la psychanalyse, la pertinence du discours pour le patient oncologique en phase agonisante, la relation entre la prévalence de la pulsion de vie et l'instinct de mort chez le patient en phase agonisante d'oncologie et ce qui signifie que le cancer est important au sujet. L'importance de la parole pour les patients atteints d'un cancer en phase moribonde est devenue perceptible, ce qui a amené une réflexion sur I'urgence de la vie du sujet, la promotion par la parole, l'élaboration du deuil dû aux pertes et la rectification subjective.
\end{abstract}

\section{INTRODUÇÃO}

O câncer é uma doença vista por muitos como traumática, pois afeta o físico, o emocional e o social do paciente oncológico em todas as suas fases, principalmente na fase terminal. Dentro deste cenário, onde os pacientes oncológicos em fase terminal sentem a dor do corpo em relação ao tratamento e também a angústia de se ver um ser finito, é perceptível que, sendo em ambiente hospitalar ou não, a importância de se fornecer a oportunidade de fala a este sujeito é inquestionável, pois nesse momento surge com maior intensidade a necessidade de falar sobre a transitoriedade da vida, mesmo com toda a dificuldade em falar sobre a morte e o morrer.

Esta dificuldade surge no sujeito, por este não colocar o tema de morte em seu contexto, tendo a morte como algo que faz parte do ciclo de vida, tornando-a, desta maneira, um tabu, um assunto que não pode ser falado. E em relação a isso, Freud (2010b) afirma que o sujeito não fala sobre a morte por desejar de maneira inconsciente, que seja um ser infinito, deseja sua imortalidade e quando surge a situação de morte é lhe atribuída uma causa, como acidente, doença ou idade avançada, mas nunca como o destino de todo ser em vida.

Tendo isto, a ausência da oportunidade de fala ao paciente oncológico em fase terminal e a sua relação com a morte, implicará na prevalência de determinada pulsão, seja ela de vida ou de morte, envolvendo-se na reação e na postura do paciente oncológico frente a sua finitude, isso sendo influenciado também, pelo significado que o significante câncer possui para o sujeito, assim como o significado do significante morte. Então, acredita-se que no momento que seja proporcionado espaço de fala ao paciente, ele poderá trazer as angústias e medos que se fazem presentes diante de sua finitude e consequentemente a possível diminuição de atitudes autodestrutivas ligadas a pulsão de morte, sabendo que na psicanálise a palavra quando verbalizada é via para a elaboração da dor e do sofrimento.

Destarte, esta pesquisa teve por objetivo, analisar à luz da 
psicanálise a relevância do falar para o paciente oncológico em fase terminal, tal como identificar os principais conceitos da psicanálise para pensar a morte e a elaboração da finitude do sujeito e apresentar a importância da palavra do paciente oncológico em fase terminal diante do analista.

Levando a analisar também que o tempo cronológico não fará tanta diferença para que seja alcançado algum resultado, pois a partir do momento que é ofertado espaço de fala para o paciente oncológico em fase terminal, ele o usará, por vezes poderá apresentar alguma resistência, mas o usará de alguma forma, utilizando linguagem que vai para além da fala, da palavra, fazendo retornar a ideia de que é tudo no tempo do sujeito, então em seu tempo, ele falará, ele irá elaborar suas perdas, seu luto.

\section{Câncer como significante}

Américo (2009) pontua que, o reconhecimento do processo de morte do paciente é uma das tarefas mais difíceis a serem realizadas, isso implica em perceber que em determinado momento da evolução do paciente, as disfunções serão irreversíveis, desta forma todo o tratamento que visa prolongar a vida, causará o prolongamento do sofrimento do paciente. Neste momento, quando é falado ao paciente sobre a evolução do câncer e a ausência de meios médicos para controlar tal avanço, o paciente passa a enxergar com maior clareza a fragilidade e o ciclo de sua vida, fazendo-se assim ser necessário que seja oportunizado, com enorme importância, assim como quando é realizado o diagnóstico, momentos de escuta, onde o paciente poderá falar sobre a angústia que faz-se presente.

Garcia-Roza (2005), traz pontos importantes para que seja possível compreender o porquê de considerar-se aqui o câncer como um significante, partindo primeiramente do esclarecimento das ideias de Saussure e posteriormente de Lacan sobre os conceitos de significado e significante. O exemplo que o autor apresenta em sua obra sobre a ideia de Saussure é o conceito de signo linguístico sendo uma unidade composta por duas partes, o significado e o significante, sendo ilustrado por Saussure com o desenho da árvore. Em linhas mais gerais, o signo não é a união de um nome a uma coisa, mas sim a união de um conceito e uma imagem acústica, ou até mesmo a uma impressão psíquica do som.

Segundo o autor, Lacan inverteu a representação do signo proposta por Saussure, colocando na seguinte ordem, significante/significado. Lacan também considerou a barra que os separa, indicando a autonomia do significante em relação a um significado, ilustrando a ideia utilizando o mesmo segmento que Saussure, apenas substituindo as figuras, pois enquanto Saussure a representou com a palavra "árvore"/figura de uma árvore, Lacan representou-a com as palavras "homem", "mulher"/figura de duas portas idênticas. Tal imagem de Saussure foi tida por Lacan como defeituosa, pois privilegiava o significado, assim como impõe o isolamento do signo através da relação biunívoca indicada pelas setas verticais, já Lacan considera sua imagem mais correta, tem-se a oposição entre os significantes, o que irá produzir a diferenciação entre os significados.

Tendo isto, Jorge (2000) reconhece que não se pode separar o significante de seu significado, porém sabe-se que há primazia no significante, ou seja, o seu alto valor perante o significado. No entanto, é necessário que compreenda-se que não é retirado o valor do significado, cada um possui seu valor diante do outro, porém, o significado é pertencente a cada sujeito, enquanto o significante é único no processo, ou seja, a palavra será a mesma (significante) e o que mudará será o significado para cada sujeito.

A partir disso, foi desenvolvido nesta pesquisa, a relação do sujeito com o significante câncer, de acordo com o que os autores Gomes et al. (2009) observam, sobre as conotações negativas que a palavra câncer possui na sociedade, sendo uma doença estigmatizante, tendo, assim, como possível significado, a morte, o que preocupa e gera angústia no paciente e seus familiares, principalmente devido a morte não ser vista como desfecho para tudo que é vivo e não ser um dos assuntos presentes nas conversas em meio à sociedade.

Desde o nascimento, o ser humano é um ser de linguagem, como afirmam Castro-Arantes e Bianco (2013), pontuando que mesmo não falando é falado, isto sendo por parte da mãe ou função materna e é essencial para a vida do sujeito, principalmente para questões de sobrevivência. Todavia, em determinado momento da fase de vida da criança, há a castração simbólica, que consiste no momento em que a criança, seja menino ou menina, passa a perceber em suas relações primárias que, o pai ou a mãe, não são suas propriedades e necessitará buscar outro objeto de amor, assim segundo Moretto (2002), este deixa de ser o falo e passa a ser um ser independente de um personagem.

Portanto, pensa-se que o câncer assume então, a posição de mais que o símbolo de algo, torna-se o significante relacionado a uma significação, que irá depender das experiências do sujeito, neste caso, possivelmente ligada aos desejos e angústias no sujeito que recebera a notícia de fim de meios medicinais para o tratamento e controle do avanço da doença, deparando-se com a sua finitude e a possível não aceitação de que a morte faz parte do ciclo da vida e que é necessário que fale-se dela.

\section{Angústia e castração}

A angústia surge na psicanálise em 1917, quando Freud (2014) em seu texto Angústia (1917), a apresenta como 
estado afetivo e é trabalhada em todo o percurso da psicanálise como eixo central da clínica das neuroses. Jorge (2007) considera que a angústia neste primeiro momento é um intenso afeto de desprazer vinculado a sexualidade do sujeito.

Segundo Leite (2011), desde que o ser humano nasce, vivencia perdas e em decorrências as estas perdas, se torna um ser desejante, pois ao perder objetos, necessita ir em busca de outros, assim, suportar a perda de um objeto amado, é também suportar a falta do objeto, vivenciando desta forma, a angústia de castração, vindo a ser a angústia, conforme a autora afirma, sempre a angústia de castração. Sendo esta, a segunda teoria freudiana, que como Jorge (2007) coloca, trata-se de uma reação a perda e ao medo de castração, ligada essencialmente ao eu.

Para que seja possível compreender a angústia de castração no paciente oncológico em fase terminal, é necessário ser pontuada a teoria freudiana sobre o complexo de Édipo. Conforme é colocado por Costa (2007), Freud faz referência ao complexo de Édipo desde 1987, mas não é encontrado um artigo específico em suas obras destinado exclusivamente para desenvolvê-lo, com exceção apenas do texto A dissolução do complexo de Édipo (1924). Neste texto, Freud (2011a) apresenta tal tema como um fenômeno central do período sexual da primeira infância e que posteriormente vem a desaparecer, surgindo então o período de latência.

A primeira vez que a criança vivencia a angústia é quando há distanciamento da mãe, mesmo que por breve espaço de tempo, ocorre então o medo de perder sua mãe por parte da criança. Esta angústia se dá, conforme Freud (2011b), quando a criança reage ao medo de ser abandonada, e nesta situação o Eu que é ligado a identificação do sujeito em sua construção com o objeto amado, tende a reagir ao medo do abandono pelo Super-eu-protetor, este que deveria mergulhar nas raízes do Isso, que trata-se de conteúdos pulsionais e inconscientes, para exercer a função de juiz e protetor em relação ao Eu, a mãe, por exemplo, para que não exista mais o medo contra os perigos, incluindo a castração.

Para Freud (2011b) em Inibição, sintoma e angústia (1926), toda angústia é angústia de castração, pois a angústia é inteiramente ligada a situações de perigo, perigo este que o menino enfrenta em meio ao complexo de Édipo e ao medo de perder seu pênis, o que o diferencia da menina; e quando se trata do medo da morte, também há ligação com a castração, devido a um perigo mortal que o sujeito experimenta, em casos de pacientes oncológicos em fase terminal.

A angústia de castração no paciente terminal, como apresenta Gonçalves (2001), se dá em decorrência do medo de ser separado de algo muito valioso para o sujeito, este medo da morte é análogo ao medo da castração, vindo tal angústia ser definida como uma reação a situações de perigo que ameacem a integridade do sujeito em situações de doença, a exemplo do que é pesquisado, a ameaça real da morte do paciente oncológico em fase terminal.

A partir disso, a angústia de castração no paciente oncológico em fase terminal, se faz presente pelo medo da morte, de algo que é desconhecido e não pode ser experimentado pelo sujeito e, como ser desejante, o paciente oncológico se vê diante da ausência da possibilidade de buscar outros objetos, diante dos objetos que perdeu, como o seu trabalho, a família e um ideal.

Com isso, a angústia no paciente oncológico em fase terminal, pode vir a ser vista como ligada ou que surge por meio do somático, onde, a partir do surgimento da real possibilidade de morte, o sujeito venha apresentar seu sofrimento no corpo, por meio de outras doenças e dores ou agravamento de maneira inesperada da fase do câncer, em fases mais iniciais, por exemplo. Portanto, a angústia de castração se dá pelo medo de perder algo de grande valor para o sujeito, o que torna possível o pensar sobre a dificuldade de nomeação da doença que o paciente vem apresentar, evitando o que lhe assusta, Ihe causa medo, medo de morrer e ao trazer o significante câncer, por exemplo, acabaria por presentificar a morte, sua finitude.

\section{O simbólico na psicanálise}

Para a compreensão do simbólico, é necessário o retorno ao estádio do espelho, teoria lacaniana. Segundo Garcia-Roza (2005), este é o momento em que a criança percebe sua imagem no espelho, espelho este que pode ser o objeto ou estar em face com outra pessoa. Tal experiência é fundamental para o indivíduo, é onde há uma matriz para a formação do esboço do ego, porém, não se deve ter essa fase do espelho como o momento de constituição do sujeito, tal só será formado quando ocorrer a passagem do imaginário ao simbólico, por meio da linguagem.

Para Lacan (2005), o simbólico trata-se de símbolos organizados na linguagem e desta forma, funcionam a partir da articulação entre significante e significado, sendo equivalente a própria linguagem, podendo vir em situação analítica por meio de sintomas reais, atos falhos ou algo que surja e que se inscreva no que seja encontrado e reencontrado incessantemente, no entanto, apesar de Lacan considerar o simbólico por meio da linguagem, também ressalta que esse ultrapassa a fala.

O simbólico pertence como componente dos três registros lacanianos, onde em 1953, Lacan os apresentou com tal nomenclatura, também conhecidos como RSI (Real, Simbólico e Imaginário). E a partir disto, Lacan questiona-se sobre o que é palavra, o que é símbolo, tendo como base a constatação de 
que a análise retira sua eficácia do fato de que só se desenvolve integralmente em palavras, pois o simbólico é mais que a palavra, mais que a fala, é a fala e o espaço, é a palavra e a pausa.

O simbólico é tido por Lacan, segundo Garcia-Roza (2005), como o determinante entre o real, o imaginário, sendo o real aquilo que é barrado, o impossível de ser definido, o que não é possível de simbolização, todavia, só é apreendido por meio do simbólico, podendo ser tido como a pulsão na teoria freudiana. E o simbólico é a Ordem, a Lei que consiste na proibição, ligado também a castração citada anteriormente; é o que vai distinguir o homem do animal e funda o inconsciente. Tal ordem é a ordem humana, é transindividual na medida em que irá preceder o sujeito e é na condição de intermédio dele que o imaginário poderá constituir-se.

Lacan (1983) chama a atenção dos analistas para a constituição das subjetividades, propõe que a psicanálise é uma práxis que aborda o real pelo simbólico, esse tido como a dimensão do discurso, do dizer, daquilo que é constituído através da associação livre que perpassa pelo campo da fala, do falar livremente sem o planejamento prévio do paciente.

Portanto, o simbólico é ligado ao inconsciente na teoria lacaniana e funciona como um sistema, um conjunto de posições e lugares, desta forma, quando Lacan traz que o inconsciente é estruturado como uma linguagem, refere-se ao inconsciente corresponder às formas simbólicas, por exemplo, em narrativas que envolvem as relações do sujeito. Neste caso, é possível pensar no paciente oncológico em fase terminal. Segundo Rasia (2006), para que o paciente não fique preso ao imaginário, recusando-se a atravessar e simbolizar a doença e seus efeitos, não ficando submetido às pressões do imaginário, podendo ocorrer isso somente por via da linguagem, da palavra.

\section{Morte e psicanálise}

Mesmo que o ser humano possua conhecimento que um dia morrerá, o falar sobre a morte ainda é negado, sendo inconscientemente um desejo pela imortalidade. Freud (2010c), ao falar sobre a transitoriedade, ilustra sua explicação utilizando uma história vivenciada com um amigo, ao ver a passagem de uma estação e a mudança da paisagem, Freud observa que exigimos nossa imortalidade e, por mais doloroso que seja ao sujeito reconhecer sua incompletude e sua impossibilidade de ser um ser imperecível, é necessário admitir a sua mortalidade, assim como o fato da vida ser transitória, sendo assim um ser finito.

Freud (2010b), em seu texto Considerações atuais sobre a guerra e a morte (1915), traz que apesar de saber que a morte é incontestável, nos negamos a falar sobre ela, principalmente nossa própria morte, fazemos isso com a finalidade de eliminá-la, pois a própria morte é inconcebível e mesmo que tentemos imaginá-la seremos apenas observadores. O que Castro-Arantes (2016) reforça, como sendo uma incapacidade do sujeito vivenciar a própria morte, compreende-se então que de sua própria morte não é falada, tendo em vista que é impossível, por ser desconhecida e não haver experiência de morte do próprio sujeito para que o faça pensar sobre e venha elaborar sua finitude, sem que seja sabedor do prazo de vida.

Isso ocorre, segundo Freud (2010c), porque o sujeito está convencido inconscientemente que é imortal e ninguém acredita em sua finitude. Um exemplo que o autor traz sobre isso é o homem civilizado evitar falar sobre a sua e a morte de outra pessoa, quando essa pode ouvir, estando com alguma doença que ameace a continuação de sua vida, assim como os pacientes oncológicos em fase terminal e seus familiares. No entanto, o autor atenta para que, ao contrário dos adultos, as crianças falam e ameaçam de morte sem que se considerem duros e malvados. Entende-se então que, é no desenvolver do sujeito onde ele é conduzido e instruído a não falar sobre morte, tornando este um "assunto feio" e, assim, dificultando o pensar sobre a morte e consequentemente a elaboração dessas.

Sobre isso, Freud (1996), no texto O 'estranho' (1919), traz a estética como qualidade do sentir e não simplesmente a teoria da beleza, sendo o estranho o que pertence ao campo do amedrontador do sujeito. Dessa forma, o sujeito evita falar sobre a morte e a tem como um "assunto feio", o estranho está ligado a angústia no sujeito, angústia essa que surge com veemência ao falar sobre a morte, algo que é assustador e não familiar ao sujeito.

Ao referir-se a dificuldade de falar-se sobre o morrer, Laplanche (1985, p. 14) considera que "no inconsciente, a morte seria sempre a morte do outro, destruição ou perda provocada". Assim, o sujeito não possui acesso a algum pressentimento de sua morte, apenas através da identificação ambivalente com uma pessoa querida, onde a sua morte é desejada e ao mesmo tempo temida, desejada de maneira inconsciente, para que o sujeito possa "livrar-se" da morte e temida por ver a possibilidade real de finitude em uma pessoa próxima, o que Laplanche considera acontecer especialmente no luto.

Facó (2012), sustenta que o ser humano possui tal dificuldade em falar sobre a morte e age como se isso nunca fosse ocorrer com todo ser que está em vida, mas é inegável que todos sabem que irão morrer, todavia, não querem ser lembrados disso, preferem deixar de lado e não presentificar o pensar sobre a morte e o morrer. A morte é vista pelo sujeito, conforme afirma Freud (2010b), como algo fortuito, pois atribuímos a ela uma causa, como um acidente, doença ou idade avançada, mas não como algo necessário e que faça parte do processo de vida do sujeito. 
E para melhor compreender a transitoriedade da vida e a importância da fala, da palavra, faz-se uso aqui de um trecho do poema Os deslimites da palavra de Manoel de Barros (2016, p. 11):

$[\ldots]$

Ando muito completo de vazios.

Meu órgão de morrer me predomina.

Estou sem eternidades.

Não posso mais saber quando amanheço ontem.

Está rengo de o amanhecer.

Ouço o tamanho oblíquo de uma folha.

Atrás do ocaso fervem os insetos.

Enfiei o que pude dentro de um grilo o meu destino.

Essas coisas me mudam para cisco.

A minha independência tem algemas.

Tal poema foi escrito não em formato de poema, mas como 200 frases soltas no final de um caderno de armazém, onde um canoeiro em meio a uma das maiores enchentes do Pantanal, em 1922, vogou por 3 dias e 3 noites na água, sem comer e sem dormir e, segundo o autor do poema, teve um delírio frásico, este que consiste em uma experiência vivenciada em meio a um surto psicótico e externalizada na poesia.

No que concerne à transitoriedade, o que Manoel de Barros (2016, p. 07) traz como "voou fora da asa", em que o autor explica o poema, pode ser visto dentro da psicanálise, segundo Castro-Arantes e Bianco (2013), como a necessidade de fala, neste caso do canoeiro ao ver-se sozinho, sem alimentação e percebendo os riscos que a enchente poderia trazer à sua vida, assim como o paciente oncológico em fase terminal. E então encontrou na escrita, uma maneira de trazer ao ato, a sua angústia ao ver-se completo de vazios, sem eternidades, tendo sua dependência presa a algemas, pois, segundo as autoras, o ser humano é um ser de linguagem e mesmo não falando, é falado.

Da mesma forma, pode-se compreender o que se passa no paciente oncológico ao ver sua fragilidade diante da vida, percebendo sua finitude e predominando então, possivelmente, a pulsão de morte no sujeito, buscando sua inexistência e diminuição das tensões psíquicas, o que ocorre com a morte.

\section{A fala para a psicanálise}

A psicanálise surgiu utilizando a técnica da hipnose, quando Freud ainda trabalhava junto a Breuer, porém, como traz Freud (2012) em seu texto Contribuição à história do movimento psicanalítico (1914), que através da interpretação de sonhos trocou a hipnose pela associação livre, a regra fundamental para o analisando, associar livremente, falar sem o planejamento prévio, para que possibilite o aparecimento do inconsciente em seu discurso, dessa forma, esta troca de técnica reinaugurou a psicanálise, realizando agora um não direcionamento do paciente, somente do tratamento.

A associação livre é mais desenvolvida no texto Recomendações ao médico que pratica a psicanálise (1914), onde Freud (2010a) realiza recomendações ao profissional, que na época era desenvolvida principalmente por médicos, como Freud, e hoje já possui formação específica e linha teórica de orientação psicanalítica na formação de psicologia. Tendo isto, o autor ressalta que o analisando deve comunicar tudo o que sua auto-observação capta, assim, suspendendo toda a objeção lógica e afetiva, que possa induzi-lo a fazer uma seleção.

Será por meio da fala, do discurso do analisando, que os medos e angústias poderão ser analisados, assim como a possibilidade de interpretação de sonhos trazidos pelos pacientes. Elias (2008) complementa que enquanto o sujeito possui possibilidade de fala, caberá ao analista escutar o que ele tem a dizer, ofertando, portanto, a escuta para acolher qualquer dito, fazendo uso da atenção flutuante e, em meio a isso, Baroni e Kahhale (2011) ressaltam a importância de o analista realizar pontuações no discurso do analisando sobre questões que repetem-se e os atos falhos, possibilitando a implicação do mesmo sobre aquela determinada situação.

Observa-se que a psicanálise dispõe-se a acolher tudo o que há de avassalador, o que é impossível de suportar pelo sujeito, de acordo com as suas singularidades. $E$ ao falar sobre os efeitos do câncer em seu corpo e em seu meio, o paciente oncológico em fase terminal, segundo Ferreira e CastroArantes (2014), possibilitará em análise que sejam tratados pelo simbólico e a sua devastação pode vir a receber um lugar na linguagem, portanto, possibilitando um destino na fase final de sua vida, ou seja, o falar possui efeito para e no sujeito.

Quando trata-se da psicanálise atuando em clínica ou em ambiente hospitalar com pacientes com câncer, as recomendações serão as mesmas, pois independente da noção real do paciente em fase terminal sobre a sua morte, ainda é necessário à oferta de fala, para que esse possa falar sobre a angústia que faz-se presente, para que possa elaborar suas perdas, o luto e sejam promovidas, por meio da fala, implicações no sujeito que o levem a retificação subjetiva.

\section{Pulsão de vida e Pulsão de morte}

Freud, durante 15 anos, havia falado somente da pulsão de vida, que segundo Azevedo e Neto (2015), era dividida em 
dois grandes grupos, as de autoconservação e sexuais, esses sendo o primeiro dualismo pulsional, onde as pulsões de autoconservação que possuem a função de preservar a existência do indivíduo, do ego e as sexuais que se esforçam na busca de objetos com objetivo de preservação da espécie e satisfação sexual.

Porém, em seu texto Além do princípio do prazer (1920), Freud (2010d), traz de maneira cautelosa, a ideia de que além da pulsão de vida, o sujeito possui também a pulsão de morte, que seria o desejo de todo ser vivo retornar ao estado inorgânico, afirmando assim que, as pulsões possuem um caráter regressivo, surgindo então o segundo dualismo pulsional, as pulsões de vida e pulsões de morte.

Segundo Gutiérrez-Terrazas (2002), Freud trouxe a ideia de pulsão de morte apenas como uma hipótese e que o conceito pulsional é contraditório, pois enquanto é separada do instinto, o endógeno instintivista é reintroduzido no pulsional por meio da sexualidade, indo em contradição a afirmação de que a pulsão não está ligada ao biológico. No entanto, Garcia-Roza (2005) e Castro-Arantes e Bianco (2013) ressaltam que a pulsão não se localiza somente no psíquico, mas entre o psíquico e o corpo, com isso, interliga os dois pontos, desenvolvendo uma espécie de interação entre mental e somático.

Quando Freud, em 1920, apresentou as pulsões possuindo um caráter regressivo, relacionava a compulsão a repetição. Como destaca Machado (2015), Freud relacionou fenômenos clínicos à compulsão e a repetição que provém do campo pulsional e possui o caráter de insistência um tanto conservadoras, desta forma, explanar, pois a revista é aberta a todos os tipos de público, perguntava-se como alguém coloca-se repetidas vezes em situações dolorosas durante a vida e chegava ao consultório queixando-se. Freud, então, concluiu que há existência no funcionamento psíquico de uma tendência, uma força que possui por objetivo levar o organismo a um estado onde não existam tensões no aparelho psíquico.

Segundo Garcia-Roza (2005), enquanto a pulsão de morte tenta alcançar a concretude de seu desejo (morte), a pulsão de vida esforça-se para que esse objetivo se cumpra de forma natural. O autor enfatiza ainda que, dentro ou como parte da pulsão de vida, Freud inclui as pulsões sexuais e de autoconservação, onde a primeira vai garantir através do sêmen, a imortalidade do ser humano e a segunda seria uma manutenção do caminho do ser vivo, proporcionando sua própria sobrevivência, para que a sua morte se dê de maneira natural. Portanto, apesar do sujeito não desejar falar sobre a sua morte, esse possui a pulsão de morte que deseja alcançar o estado inorgânico.

Destarte, compreende-se assim como trazido anteriormente, a pulsão localiza-se entre o psíquico e o corpo, a partir disso, entende-se que o que atinge o corpo também irá atingir o psíquico, pois, como trazem Castro-Arantes e Bianco (2013), o sujeito é efeito do ritmo pulsional e, apesar de sujeito e pulsão não coincidirem, é inevitável não se falar sobre a constituição subjetiva sem referir-se ao campo pulsional.

\section{MÉTODOS}

Realizou-se uma pesquisa em psicanálise, que buscou, conforme afirma Couto (2010), reconstruir a teoria, os conceitos, as ideias e ideologias, tendo em vista, em termos imediatos, a busca pelo aprimoramento dos fundamentos teóricos. A pesquisa teórica é a mais utilizada em pesquisas sobre fenômenos psicanalíticos, propondo, como colocado anteriormente, a compreensão de determinados fenômenos a partir da teoria psicanalítica. Neste método de pesquisa, fazse uso de bibliografias, objetivando novas construções teóricas e concepções de fenômenos que implicam o pesquisador. Garcia-Roza (1993), complementa que um dos principais objetivos da pesquisa em psicanálise é a submissão da teoria da psicanálise a uma nova análise, verificando, portanto, as condições de sua possibilidade.

Para isto foram, portanto, utilizados artigos científicos publicados nas bases de dados de produção científica: Scielo, Pepsic e Lilacs. Assim como monografias, dissertações de mestrado, teses de doutorado, manuais e livros, devendo datar de 2009 a 2017, podendo estender-se até 2018, fazendo uso das produções cientificas mais recentes, garantindo novas análises sobre o tema, porém não deixando de fazer uso de materiais clássicos e com data inferior a estipulada, devido ao grau de relevância para a pesquisa como Sigmund Freud e Jacques Lacan. Os artigos científicos deviam atender esta estrutura, palavras-chave: "paciente oncológico", "finitude", "psicanálise", "analista hospitalar", "escuta oncológica”, "fala do paciente" e "morte". Todo o material encontrado passou por leitura seletiva e interpretativa para uma análise psicanalítica dos conteúdos de cada produção científica.

\section{RESULTADOS}

Todo o material utilizado refletiu-se em material bibliográfico, sendo estipulado o critério pela pesquisadora, de serem produções de cunho psicanalítico e de outras ciências, para falar sobre o câncer, assim, sendo utilizados preferencialmente livros dos grandes nomes da psicanálise, como Sigmund Freud e Jacques Lacan. Tendo isso, foi possível encontrar nas produções psicanalíticas textos que tratassem especificamente sobre os subtemas, como a morte e dualismo pulsional, assim como o principal, a fala do sujeito, 
a principal técnica da psicanálise, a associação livre. A partir disso, foi possível visualizar a enorme importância da oportunidade de fala para o sujeito em qualquer época de sua vida, neste caso especifico, em meio a uma doença que traz para alguns pacientes a possibilidade real de morte no discurso do médico, levando o paciente oncológico a um sofrimento psíquico.

Como foi colocado por Gomes et al. (2009), apesar dos avanços tecnológicos em meio a medicina, o câncer ainda é visto em meio a sociedade como uma doença estigmatizante, isso se dá devido à dificuldade que o sujeito possui em falar sobre a morte e o morrer, permitindo que a morte ainda seja tratada como um tabu, um assunto que não pode ser falado, assim o sujeito vindo a falar somente sobre o que é belo, pois o falar sobre a morte e o processo de morrer, gera no sujeito, certo incomodo, por ser desconhecido. Ser estranho. O estranho está ligado a angústia no sujeito, angústia esta que surge com veemência ao falar sobre a morte, algo que é assustador e não familiar ao sujeito.

E tal dificuldade em falar sobre a morte, além da forma como o sujeito deseja inconscientemente a sua imortalidade, há a angústia de castração que se faz presente no paciente oncológico em fase terminal, surgindo a partir das perdas que o sujeito passa no período de tratamento e de apontamento sobre a sua morte pelo outro. Angústia esta que surge no paciente quando este possui o medo de ser separado de algo muito valioso.

Neste trabalho, foi explorada a frequência de um significante e a variação de significados de acordo com as experiências do sujeito, isso vindo a implicar na prevalência da pulsão de vida ou pulsão de morte e consequentemente no desenvolver dos últimos cuidados no paciente oncológico, nas relações do sujeito e na maneira como o paciente se vê nessa situação diante de sua finitude. Porém, não é possível afirmar que com a prevalência da pulsão de vida, o paciente oncológico em fase terminal poderá elaborar suas perdas e conseguirá perceber sua posição diante do processo de morrer, por meio da fala, mas tal oportunidade poderá auxiliar nas implicações que são levantadas no e pelo sujeito diante de tal experiência. Para esta afirmação sobre a prevalência e o posicionamento do sujeito, é necessário que seja ouvido e analisado cada paciente, cada discurso, pois cada sujeito possui suas experiências e cada hipótese deve ser desenvolvida a partir do um a um.

É interessante o que Rasia (2006) traz sobre os três registros de Lacan analisados no paciente terminal, colocando a necessidade do sujeito simbolizar a doença e os feitos dessa, não fincando preso as pressões do imaginário e simbolizando por meio da linguagem as suas angústias e o luto devido as perdas ocorridas, a exemplo do luto temos a necessidade do paciente oncológico permanecer no hospital, o distanciamento do trabalho e da família, elaborando as vivências neste período ocorrido, levando a implicação do sujeito sobre a sua posição diante da morte.

Em relação a isso, foram analisados casos clínicos atendidos e publicados por psicanalistas/profissionais que atuam com balizamento teórico psicanalítico, para uma maior compreensão sobre o dualismo pulsional e os conceitos lacanianos de significante e significado. Baroni e Kahhale (2011) e Castro-Arantes (2016) sustentam que, apesar do sujeito saber que um dia morrerá, quando depara-se com a real possibilidade de morte, começa a indagar-se, tendo como exemplo tais falas: "o que eu fiz para merecer isso?", "por que eu?", o que gera uma angústia no paciente oncológico em fase terminal.

E a partir disso Baroni e Kahhale (2011), colocam a necessidade de o analista escutar o paciente oncológico, no desejo que surge através do significante que coloca-se, o câncer, levando em consideração o um a um. Pois a maneira como o sujeito enfrentará o diagnóstico de câncer terminal, irá possivelmente, ser influenciada pela forma com que esse vê a morte, ou seja, qual o significado que o significante câncer possui para o sujeito, assim como qual o significado do significante morte, existente para o sujeito.

Para melhor compreensão desta relação entre teoria pulsional e significante/significado, foi feito uso de fragmentos clínicos, primeiramente apresentando trechos que podem ser analisados dentro da psicanálise como uma urgência de vida.

Castro-Arantes (2016) traz o caso de A., que em meio à morte e o perder-se nela, que age, como colocou Lacan (1989), somente quando está mortalmente ferido, em meio ao curto período de tempo que lhe resta de vida, vindo recebê-la e posteriormente perder-se nela, pede sua esposa em casamento e casa-se com a mulher que vivia há 12 anos.

Outro fragmento clínico que pode ser pensado como a urgência pela vida, é trazido por Peralva (2008), que apesar de não ser um caso de um paciente oncológico em fase terminal, fará, através dos recortes, com que a compreensão seja melhor compreendida, devido as falas do paciente e até mesmo a ausência destas. O caso que a autora traz é nomeado de João, um homem de 73 anos, internado no Centro de Terapia e Tratamento Intensivo (CTI) de um hospital, diagnosticado com enfarto agudo do miocárdio, devido a complicações João precisou passar por procedimentos cirúrgicos e depois disso começou a travar uma luta diária contra a morte. João após a cirurgia estava com dificuldades para respirar e então foi realizada uma traqueostomia e além de não poder falar, o mesmo já não desejava falar.

O quadro do paciente agravou-se, e então João recebeu a notícia do médico sobre a ausência de novas possibilidades de 
tratamento para o seu caso, mas João continuava ali, debilitado, mas lúcido, ainda não havia morrido e assim como quando chegou ao CTI foi lhe ofertado espaço de fala, neste momento também foi. E assim, Peralva (2008, p. 69) relata que usou suas palavras para João, emprestando-as e algumas vezes João falava "eu vou morrer", essa fala acompanhandoo em todo o seu tempo no CTI, no entanto, em uma das vezes que a autora the perguntava se João precisava de algo, ele falou "conversar" e foi emprestando suas palavras, que Peralva pôde situá-lo do vivido, buscando no próprio relato inicial de João sobre sua vida, buscar pontos de ancoramento de seu desejo, promovendo então a retificação subjetiva do sujeito.

É possível perceber nos dois casos clínicos supracitados que, diante da urgência de vida, encontra-se também a urgência psíquica. O que Castro-Arantes (2016), coloca como uma incompreensão do que seria esse algo que faz com que o sujeito só decida casar-se no leito de morte, pode ser visto com a urgência pela possibilidade de ainda poder tomar decisões, ser dono de si, aliado a pulsão de vida do sujeito, com atitudes construtivas. Em relação à posição dos pacientes frente à possibilidade de morte dar-se-á com base nas experiências de cada sujeito, os dois casos citados, com a urgência pela vida, com o medo diante da morte e a busca pela fala para a elaboração destas perdas e decisões.

Para exemplo da prevalência da pulsão de morte, é feito uso de um fragmento clínico trabalhado por Petrilli (2015), intitulado de Ana, 17 anos de idade e em tratamento de leucemia, internada na Unidade de Terapia Intensiva (UTI). Ana ainda possuía possibilidades de tratamento, ou seja, não estava em fase terminal, apesar das complicações em seu quadro de saúde. A autora traz que Ana foi internada na UTI devido a uma tiflite com perfurações no intestino, dessa forma, Ana necessitava realizar jejum absoluto. Ana possuía um gemido ininterrupto e angustiante, tanto para ela quanto para os profissionais.

Segundo Petrilli (2015, p. 81), Ana não queria conversar e quando esse espaço era oferecido pela psicóloga, Ana falava "Você vai me dar comida? Se não vai, não pode me ajudar", entre tantas tentativas de convocar Ana a falar, não havia resultados, apenas os gemidos de dor, até que Ana lhe diz que a pior parte de toda aquela situação é a de precisar mendigar por um gole de água, e quando Petrilli lhe pergunta o porquê de Ana mendigar por algo que coloca sua vida em risco, faz com que Ana venha a ressignificar sua posição subjetiva, passando a trocar seu gemido, pela fala, passando a modificar seu comportamento e evoluindo no tratamento, perante o surgimento desta implicação.

No caso de Ana, a paciente possivelmente encontrava-se com a prevalência da pulsão de morte, partindo do princípio que Freud (2010d), caracteriza tal pulsão como sendo a busca de maneira inconsciente para o retorno ao inanimado, a diminuição das tensões psíquicas, sendo alcançado o princípio de Nirvana, com a morte. Assim, Ana de maneira inconsciente, em seu desejo pela alimentação e água, mesmo estando proibida, fazia tal solicitação, sem perceber que tal desejo realizado poderia lhe causar a morte, demonstrando atitudes autodestrutivas.

Jorge (2000), afirma que significado e significante não podem ser separados e cada sujeito possuirá o significado diferente de determinado significante, de acordo com suas experiências. Assim, o significado de câncer para o sujeito poderá ser tido de outras formas e, possivelmente, variando a forma como esse enfrentará o diagnóstico e a maneira com que o sujeito vê a morte, possuindo também, variados significados. Nesses casos clínicos outros pontos são fortemente levantados, como o desejo do analista inteiramente ligado ao fornecimento de fala ao paciente, possibilitando espaço para a palavra, mesmo quando há a recusa inicial de falar e/ou quando há a impossibilidade da fala.

Tornou-se notória a importância da fala para os pacientes terminais, levando a refletir sobre a urgência de vida do sujeito, enxergando-se diante da possibilidade de não poder mais tomar decisões, inicia um processo de ações que anteriormente ele adiava, assim como a reflexão sobre os excessos no paciente e a dificuldade de perceber-se diante da finitude, levando, dessa forma, ao sujeito solicitar e ter atitudes autodestrutivas de maneira inconsciente, reforçando que, a partir do momento que é ofertado espaço de fala ao paciente, ele o usará e possibilitará a retificação subjetiva, irá implicar-se diante de sua situação.

Portanto, com base nas leituras realizadas e nas análises dos textos, tornou-se clara a importância da fala sobre a morte para pacientes oncológicos em fase terminal, promovendo por meio da associação livre do paciente e, quando necessário, o empréstimo das palavras do analista para o paciente, possibilitando a elaboração de seu luto, tal como a compreensão sobre a força da subjetividade do paciente pelas pulsões, através de seu discurso expressando a fantasia do sujeito em relação a sua finitude, o pensar e o falar sobre ela.

\section{CONSIDERAÇÕES FINAIS}

Ao término deste percurso, nota-se a grandiosidade da psicanálise e dos vários caminhos por onde pode-se caminhar junto as suas teorias e técnicas deixadas principalmente por Sigmund Freud, e aqui pelo caminho da fala e da elaboração da morte em pacientes oncológicos em fase terminal, notando a dificuldade de fala sobre a morte do sujeito. Como 
foi colocado em toda a trajetória desta pesquisa, o sujeito deseja de maneira inconsciente a sua imortalidade, principalmente devido ao inconsciente ser atemporal e tal percepção sobre a finitude do sujeito, por vezes, vir à tona somente quando este depara-se com a real possibilidade de morte, como no surgimento de uma doença, como, neste caso, o câncer em fase terminal.

Isso se dá, segundo Freud (2010b), porque sempre buscamos uma causa para a morte e não a temos como parte do ciclo de vida, e quando ocorre, Ihe atribuímos uma justificativa, como uma doença, um acidente ou idade avançada e não como um ciclo que se completou. Assim como o sujeito não aceita a morte, também evita falar sobre ela, tendo a morte como um assunto que deva ser evitado, tornando-a um tabu, mesmo sabendo que irá morrer um dia, como coloca Facó (2012), o sujeito evita falar sobre ela e não presentificar, deixando-a de lado.

No entanto, isso não é generalizado, existem pessoas que possuem um posicionamento diferente diante da morte e até mesmo no falar sobre a morte e o processo de morrer em seu contexto social, isso se dá conforme as suas relações e experiências, tanto o negar como o aceitar. A partir de disso, pensou-se na prevalência de determinada pulsão no sujeito, seja ela de vida ou de morte, vindo a interferir nas relações, seja ela com o processo de diagnóstico final em meio a um ambiente hospitalar, envolvendo medicações, a equipe e a família, tal como a própria posição do sujeito frente à doença e a sua finitude. A prevalência de determinada pulsão será implicada principalmente de acordo com as experiências do sujeito com a morte, o que também irá ser apresentado na maneira como o paciente oncológico em fase terminal reagirá diante da notícia de ausência de meios médicos para o controle do avanço da doença.

A fala neste momento faz-se necessária, tanto quanto no diagnóstico inicial com muitas possibilidades de cura e, por mais que possa ser pensado que para possibilitar fala a um sujeito é necessário tempo indeterminado, é possível que em breve tempo cronológico e em ambiente hospitalar ou clínico, o sujeito, o paciente oncológico poderá falar e elaborar suas perdas, elaborar sua posição diante da doença e da morte. Assim, será com base nas experiências do sujeito que a força da subjetividade irá perpassar pela pulsão de vida e pulsão de morte, através de sua fala expressando os sentimentos a respeito de sua fantasia em relação à morte e o atravessamento da mesma para que possa pensar a finitude.

\section{REFERÊNCIAS}

AZEVEDO, Monia Karine; NETO, Gustavo Adolfo Ramos Mello. O desenvolvimento do conceito de pulsão de morte na obra de Freud. Revista Subjetividades, v. 15, n. 1, p. 67-75, 2015. DOI: http://dx.doi.org/10.5020/23590777.15.1.6775 Disponível em:

http://periodicos.unifor.br/rmes/article/view/4520.

Acesso em: 11 de jun. 2018.

BARONI, Claudia Sofia Ferrão; KAHHALE, Edna Maria Peters. Possibilidades da psicanálise lacaniana diante da terminalidade: uma reflexão sobre a clínica da urgência. Revista Psicologia Hospitalar, v. 9, n. 2. São Paulo, jul. 2011. Disponível em: http://pepsic.bvsalud.org/scielo.php?script=sci_arttext\& pid=S1677-74092011000200004. Acesso em: 11 de jun. de 2018.

BARROS, Manoel de. Os deslimites da palavra. In: O livro das ignorãças. Rio de Janeiro: Alfaguara, 2016, 07-11 p.

CASTRO-ARANTES, Juliana de Miranda; BIANCO, Anna Carolina Lo. Corpo e finitude - a escuta do sofrimento como instrumento de trabalho em instituição oncológica. Ciência e Saúde Coletiva, n. 18, p. 2515-2522, 2013. Disponível em: http://www.scielo.br/pdf/csc/v18n9/v18n9a05.pdf. Acesso em: 11 de jun. de 2018.

CASTRO-ARANTES, Juliana. Os feitos não morrem: psicanálise e cuidados ao fim da vida. Revista Ágora, v. 19, n. 3, p. 637648, 2016. Disponível em: http://www.scielo.br/pdf/agora/v19n3/1809-4414agora-19-03-00637.pdf. Acesso em: 11 de jun. de 2018. COSTA, Teresinha. Psicanálise com crianças. Edição Psicanálise passo-a-passo, v. 75. Rio de Janeiro: Jorge Zahar, 2007.

COUTO, Luis Flávio. Quatro modalidades de pesquisa em psicanálise. In: Pesquisa em Psicanálise: transmissão na Universidade. Fuad Kyrillos, Jacqueline Oliveira Moreira (Org.), Barbacena, MG: EdUEMG, 2010, 59-80 p.

ELIAS, Valéria de Araújo. Psicanálise no hospital: algumas considerações a partir de Freud. Revista da SBPH, v. 11, n. 1. Rio de Janeiro, p. 87-100, jun. 2008. Disponível em: http://pepsic.bvsalud.org/scielo.php?script=sci_arttext\& pid=S1516-08582008000100007. Acesso em: 11 de jun. de 2018.

FACÓ, Maria Lopes. A angústia na clínica: pacientes com câncer. 2012. Tese (Doutorado em Teoria Psicanalítica) Universidade Federal do Rio de Janeiro - UFRJ, 2012.

FERREIRA, Deborah Melo; CASTRO-ARANTES, Juliana de Miranda. Câncer e corpo: uma leitura a partir da psicanálise. Analytica: Revista Psicanálise, v. 3, n. 5, São João del Rei, p. 37-71, 2014. ISSN: 2316-5197. Disponível em:

http://www.seer.ufsj.edu.br/index.php/analytica/article/ view/585. Acesso em: 11 de jun. de 2018.

FREUD, Sigmund. O 'estranho' (1919). In: Uma neurose infantil e outros trabalhos (1917-1918). Obras psicológicas 
completas de Sigmund Freud: edição standard brasileira, Rio de Janeiro: Imago, 1996, 235-269 p.

FREUD, Sigmund. Recomendações ao médico que pratica a psicanálise (1912). In: Observações psicanalíticas sobre um caso de paranoia relatado em autobiografia ("o caso Schreber"), artigos sobre técnicas e outros textos (19111913). Tradução de Paulo César de Souza. Obras Completas, v. 10, São Paulo: Companhia das Letras, 2010a, 112-123 p.

FREUD, Sigmund. Considerações atuais sobre a guerra e a morte (1915). In: Introdução ao narcisismo, ensaios de metapsicologia e outros textos (1914-1916). Tradução de Paulo César de Souza. Obras Completas, v. 12, São Paulo: Companhia das Letras, 2010b, 157-185 p.

FREUD, Sigmund. A transitoriedade (1916). In: Introdução ao narcisismo, ensaios de metapsicologia e outros textos (1914-1916). Tradução de Paulo César de Souza. Obras Completas, v. 12, São Paulo: Companhia das Letras, 2010c, 186-190 p.

FREUD, Sigmund. Além do princípio do prazer (1920). In: História de uma neurose infantil ("o homem dos lobos"), além do princípio do prazer e outros textos (1917-1920). Tradução de Paulo César de Souza. Obras Completas, v. 14, São Paulo: Companhia das Letras, 2010d, 121-179 p.

FREUD, Sigmund. A dissolução do complexo de Édipo (1924). In: O eu e o id, "autobiografia" e outros textos (19231925). Tradução Paulo César de Sousa. Obras Completas, São Paulo: Companhia das Letras, 2011a, 203-213 p.

FREUD, Sigmund. Inibição, sintoma e angústia (1926). In: Inibição, sintoma e angústia (1926-1929). Tradução Paulo César de Sousa. Obras Completas, v. 17 São Paulo: Companhia das Letras, 2011b, 10-99 p.

FREUD, Sigmund. Contribuição à história do movimento psicanalítico (1914). In: Totem e tabu, contribuição à história do movimento psicanalítico e outros textos (19121914). Tradução de Paulo César de Souza. Obras completas, 1. ed., v. 11, São Paulo: Companhia das Letras, 2012, 245-327 p.

FREUD, Sigmund. A angústia (1917). In: Conferências introdutórias à psicanálise (196-1917). Tradução Sergio Tellaroli. Obras Completas, v. 13, São Paulo: Companhia das Letras, 2014, 422-442 p.

GARCIA-ROZA, Luiz Alfredo. A pesquisa acadêmica em psicanálise. In: ROPA, D. (Org). Anuário Brasileiro de Psicanálise. Rio de Janeiro: Relume Dumará, 1993 p. 118121.

GARCIA-ROZA, Luiz Alfredo. Pulsão e representação. In: Freud e o inconsciente. 24. ed. Zahar, 2005.

GIL, Antônio Carlos. Como elaborar projetos de pesquisa. 4. ed. São Paulo: Atlas, 2008.

GOMES, Cláudio Henrique Rebello; SILVA, Patrícia Veloso;
MOTA, Fernando Freitas. Comunicação do diagnóstico de câncer: análise do comportamento médico. Revista Brasileira de Cancerologia, p.139-143, Out. 2009. Disponível em: http://www1.inca.gov.br/rbc/n_55/v02/pdf/07_artigo4.p df. Acesso em: 11 de jun. de 2018.

GONÇALVES, Mônica de Oliveira. Morte e castração: um estudo psicanalítico sobre a doença terminal infantil. Revista de Psicologia: ciência e profissão, v. 21, n. 1, Mar. 2001. DOI: http://dx.doi.org/10.1590/S1414$98932001000100004 . \quad$ Disponível em: http://www.scielo.br/scielo.php?script=sci_arttext\&pid= S1414-98932001000100004. Acesso em: 11 de jun. de 2018.

JORGE, Marco Antonio Coutinho. Inconsciente e linguagem: o simbólico. In: Fundamentos da psicanálise de Freud a Lacan: as bases conceituais. v. 1. Rio de Janeiro: Jorge Zahar, 2000.

JORGE, Marco Antonio Coutinho. Angústia e castração. Teoria Psicanalítica Reverso, v. 29, n. 54, p. 37-42, Set. 2007. Disponível em: http://pepsic. bvsalud.org/scielo.php?script=sci_arttext\&pid=S010273952007000100006. Acesso em: 11 de jun. de 2018.

LACAN, Jacques. Desmontagem da pulsão In: O seminário. Livro 11: os quatro conceitos fundamentais da psicanálise, 1964. Versão brasileira de M. D. Magno. 2. ed., Jorge Zahar Editor Ltda., 1985, 153-164 p.

LACAN, Jacques. Hamlet, por Lacan. In: Shakespeare, Duras, Wedekind, Joyce. Tradução de Eunice Martinho. Lisboa: Assírio e Alvim, 1989.

LACAN, Jacques. Do "Trieb" de Freud e do desejo do psicanalista. In: Escritos. Rio de Janeiro: Jorge Zahar Editor, 1998, 865-868 p.

LAPLANCHE, Jean. Vida e morte em psicanálise. Tradução de Cleonice Paes Barreto Mourão e Consuelo Fortes Santiago. Artes Médicas: Porto Alegre, 1985. E-book.

LEITE, Sonia. Freud e as duas teorias da angústia. In: Angústia. Edição Psicanálise passo-a-passo, Rio de Janeiro: Zahar, 2011, 32-54 p. E-book.

MACHADO, Silvio Memento. Psicanálise e cuidados paliativos: do sem-sentido à invenção. Revista da Universidade Vale do Rio Verde, Três Corações, v. 13, n. 2, p. 613-618, 2015. DOI: $\quad$ http://dx.doi.org/10.5892/ruvrd.v13i1.2445. Disponível em: http://periodicos.unincor.br/index.php/revistaunincor/ar ticle/view/2445. Acesso em: 11 de jun. de 2018.

MARCONI, Maria de Andrade; LAKATOS, Eva Maria. Técnicas de pesquisa: planejamento e execução de planejamento e execução de pesquisas, amostragens e técnicas de pesquisa, elaboração, análise e interpretação de dados. 5. ed. São Paulo: Atlas 2002. 
MINAYO, Maria Cecília de Souza Pesquisa Social: teoria, método e criatividade. Petrópolis, RJ: Vozes, 2001.

MORETTO, Maria Lívia Tourinho. O que se faz quando se faz psicanálise? In: O que pode um analista no hospital?, Casa do Psicólogo, 2002, 19-60 p.

PERALVA, Elisa Lima Mayerhoffer. O confronto com a finitude na clínica hospitalar: da morte como limite à urgência da vida. Revista Práxis e Formação, UFRJ - RJ, p. 65-72, 2008.

Disponível

em: http://www.praxiseformacao.uerj.br/revistaXI/pdf/ a0607ar11.pdf. Acesso em: 11 de jun. de 2018.

PETRILLI, Renata de Toledo. Intervenções psicológicas em pacientes submetidos à procedimentos invasivos em um serviço de oncologia pediátrica. Revista Sociedade Brasileira de Psicologia Hospitalar, v. 18, n. 2, Rio de Janeiro, p. 74-88, Dez. 2015. Disponível: http://pepsic.bvsalud.org/scielo.phpscript=sci_arttext\&pi $d=S 1516-08582015000200006$. Acesso em: 11 de jun. de 2018.

RASIA, José Miguel. Imaginário e simbólico em pacientes com câncer: análise de suas narrativas. Mediações - Revista de Ciências Sociais, v. 11, n. 2, 2006. DOI: http://dx.doi.org/10.5433/2176-6665.2006v11n2p65.

Disponível

em: http://www.uel.br/revistas/uel/index.php/mediacoes/art icle/view/8981. Acesso em: 11 de jun. de 2018.

Submissão: 08/01/2020

Aprovado para publicação: 16/02/2020 